\title{
Beliefs and attitudes towards mental illness: An examination of the sex differences in mental health literacy in a community sample
}

Ray Gibbons, Einar B Thorsteinsson, Natasha M Loi

Objectives: The current study investigated mental health literacy in an Australian sample to examine sex differences in the identification of and attitudes towards various aspects of mental illness. Method: An online questionnaire was completed by 373 participants $(M=$ 34.87 years). Participants were randomly assigned either a male or female version of a vignette depicting an individual exhibiting the symptoms of one of three types of mental illness (depression, anxiety, or psychosis) and asked to answer questions relating to aspects of mental health literacy. Results: Males exhibited poorer mental health literacy skills compared to females. Males were less likely to correctly identify the type of mental illness, more likely to rate symptoms as less serious, to perceive the individual as having greater personal control over such symptoms, and less likely to endorse the need for treatment for anxiety or psychosis. Conclusion: Generally, the sample was relatively proficient at correctly identifying mental illness but overall males displayed poorer mental health literacy skills than females. 

Beliefs and attitudes towards mental illness: An examination of the sex differences in mental health literacy in a community sample

8

15 Correspondence concerning this article should be addressed to:

16 Einar B. Thorsteinsson

17 Psychology, School of Behavioural, Cognitive and Social Sciences, University of New England, NSW

18 2351, Australia

19 Email: ethorste@une.edu.au 
Abstract

23 Objectives: The current study investigated mental health literacy in an Australian sample to examine

24 sex differences in the identification of and attitudes towards various aspects of mental illness.

25 Method: An online questionnaire was completed by 373 participants $(M=34.87$ years $)$. Participants

26 were randomly assigned either a male or female version of a vignette depicting an individual exhibiting

27 the symptoms of one of three types of mental illness (depression, anxiety, or psychosis) and asked to

28 answer questions relating to aspects of mental health literacy.

29 Results: Males exhibited poorer mental health literacy skills compared to females. Males were less

30 likely to correctly identify the type of mental illness, more likely to rate symptoms as less serious, to

31 perceive the individual as having greater personal control over such symptoms, and less likely to

32 endorse the need for treatment for anxiety or psychosis.

33 Conclusion: Generally, the sample was relatively proficient at correctly identifying mental illness but

34 overall males displayed poorer mental health literacy skills than females.

36 Keywords: sex; public belief; mental illness; mental health literacy; vignette 
Mental illness is a predominant issue in public health, contributing to substantial economic and

emotional community burden. It is estimated that up to $45 \%$ of the Australian population will experience mental illness at some point during their lifetime (Australian Bureau of Statistics [ABS], 2009). However, not all individuals who experience symptoms of mental illness receive the same level of care or treatment. This is partly attributable to the general public's beliefs and attitudes surrounding mental illness, often referred to as their mental health literacy (e.g., Jorm, Barney et al., 2006).

The term mental health literacy was first introduced in a study by Jorm et al. (1997) investigating public beliefs about the causes and risk factors for depression and schizophrenia. Jorm et al. (1997, p. 143) described a person's mental health literacy as his or her "knowledge and beliefs about mental disorders that aid the recognition, management or prevention of these disorders." According to Jorm et al. (1997), mental health literacy includes: (a) the ability to recognize and differentiate various types of mental illness and disorders; (b) knowledge of how and where to seek information about risk factors, intervention strategies, and professional help; and (c) attitudes and beliefs that influence a person's ability to identify mental illness and seek appropriate help. Furthermore, an individual's mental health literacy can be influenced by a multitude of factors, including age, remoteness of residency, education, socioeconomic status, and personal experience with mental healthcare (Dahlberg, Waern \& Runeson, 2008; Farrer, Leach, Griffiths, Christensen \& Jorm, 2008; Griffiths, Christensen \& Jorm, 2009; Kaneko \& Motohashi, 2007).

Studies have shown that the general public historically exhibit poor mental health literacy towards various aspects of mental illnesses (Goldney, Fisher \& Wilson, 2001; Jorm et al., 1997; Jorm, Christensen \& Griffiths, 2005). For instance, Jorm et al. (1997) revealed that only 39\% of Australian respondents could accurately recognize symptoms of depression. The beliefs and attitudes of the general public has been shown to be frequently discordant with those held by mental health 
62 professionals, with the public frequently viewing medication, hospitalisation, and psychiatric treatment

63 as harmful (Goldney et al., 2001; Jorm et al., 1997). A study by Link, Phelan, Bresnahan, Stueve and

64 Pescosolido (1999) showed that many symptoms and disorders are not accurately identified by the

65 public as being a mental illness. The results indicated that while there was an overall improvement in

66 mental health literacy, with the public more ably recognizing depression, more positively rating a range

67 of interventions, and holding beliefs and attitudes more consistent with those of mental health

68 professionals, gains still need to be made with respect to schizophrenia and anxiety disorders which are

69 still under-recognised. Interestingly, according to Andrews (1999, p. 317), both mental health "patients

70 and the media do not distinguish between the non-specific help from counsellors and the specific

71 treatment to be expected from mental health professionals". This inability to discriminate between the

72 types of services offered suggests that the general public's mental health literacy is still largely lacking

73 (Goldney et al., 2001; Jorm et al., 2005; Jorm \& Kelly, 2007) even for high prevalence disorders such

74 as depression, anxiety, and psychosis.. An individual's mental health literacy, including his or her

75 beliefs and attitudes towards mental illness, therefore, may influence or contribute to the formulation of

76 'lay appraisals'.

77 Evidence suggests that long before an individual sees a mental health professional, 'lay

78 appraisals' or 'lay diagnoses' are made by individuals, family members, friends, and co-workers

79 regarding the early signs of mental illness (Hollingshead, 2007). Given the pervasiveness of these

80 disorders (e.g., ABS, 2008; Sane Australia, 2014), individuals often have assumptions regarding

81 prognosis as well as opinions relating to the perceived seriousness of the condition, help-seeking or the

82 need for treatment (Angermeyer, Matschinger \& Holzinger, 1998), and the amount of control they

83 exert over the disorder itself. Lay appraisals are frequently responsible for determining how and when

84 an individual receives treatment for his or her mental illness (Greenley \& Mechanic, 1987; 
85 Pescosolido, Gardner \& Lubell, 1998). As a result, a large portion of people remain undiagnosed and 86 untreated (Burgess et al., 2009; Kessler et al., 1994).

87 Some findings suggest that sex differences exist when it comes to public attitudes and beliefs towards mental illness (e.g., Angermeyer et al., 1998; Cotton, Wright, Harris, Jorm \& McGorry, 2006;

89 Holzinger, Floris, Schomerus, Carta \& Angermeyer, 2012; Jorm et al., 1997), with Holzinger et al.

90 (2012) confirming that females are more likely to advocate professional help than males and female

91 patients are likely to face less societal rejection than male patients. With respect to prevalence of

92 mental illness, females are seen as being at a greater risk of developing mood and anxiety disorders

93 than males (e.g., Alonso et al., 2004). Regarding mental health literacy, Cotton et al. (2006)

94 investigated young Australians between 12 and 25 years of age. They also revealed that male youths

95 exhibited significantly worse recognition of depressive symptoms than female youths, with $61 \%$ of

96 females able to correctly identify depression compared to $35 \%$ of males. Furthermore, male youths

97 were less likely than female youths to view seeing a psychologist or counsellor as an appropriate

98 treatment for psychosis. Furthermore, Holzinger et al. (2012, p. 74) attest that females are more

99 informed about mental illness than males as they have "A stronger tendency to...to conceive problems 100 in psychological terms...."

101 These studies provide evidence that some sex differences in the mental health literacy of the 102 general public exists. However, it is unknown to what extent such differences currently exists in the 103 Australian general adult population. Expanding our knowledge of sex differences in public awareness 104 of mental illness could help to identify particular areas of mental health literacy in need of 105 improvement specific to each sex. High mental health literacy, including the ability to accurately 106 identify mental illness, may play a pivotal role in help-seeking behaviors and potentially decrease an 107 individual's vulnerability to suicide, particularly for males (Kaneko \& Motohashi, 2007). Additionally, 108 the identification of such sex disparities in mental health literacy would help to facilitate and guide 
109 education programs about mental health, as well as tailor specific individual psycho-education unique 110 to each client.

111 One of the aims of this study was to build upon the current findings associated with mental health

112 literacy by investigating further the influence that sex has regarding the identification of, and attitudes

113 towards, various aspects of the three major types of mental illness in Australia (i.e., depression,

114 anxiety, and psychosis). As such, the hypotheses are as follows: (1) the general public's mental health

115 literacy is likely to differ significantly for depression, anxiety, and psychosis reflected in an association

116 between identification and type of mental illness, (2) various aspects of the general public's mental

117 health literacy (correct identification) toward depression, anxiety, and psychosis are likely to differ

118 significantly between males and females, and (3) the sex of the individual expressing symptoms of

119 depression, anxiety, and psychosis is likely to influence the general public's mental health literacy. We

120 also examined predictors of (a) the need for treatment, (b) perceived level of control over mental

121 illness, and (c) the perceived susceptibility of each sex to mental illness.

\section{Materials \& Methods}

\section{Participants}

The participants consisted of 381 respondents of varying age, sex, and socio-demographic

125 backgrounds. Eight participants discontinued the questionnaire before completing all of the initial

126 socio-demographic background section and were excluded. The final sample of individuals who

127 participated in this study consisted of 373 participants between the ages of 18 and $84(M=34.87, S D=$

128 12.46) with $28 \%(n=106)$ of participants being male $(M=35.95, S D=12.72)$, compared to $72 \%(n=$

129 267) being female $(M=34.44, S D=12.36)$.

130 Participants were recruited to complete the online questionnaire, created in Qualtrics

131 (www.qualtrics.com), via invitation email through various mailing lists and via messages posted on

132 various social networking sites such as Facebook and Twitter, and by word of mouth. All participants 
133 accessed the study via the provided URL. The study was approved by the University of New England's

134 Human Research Ethics Committee (HE11/022).

\section{Materials and Procedures}

After reading the online information sheet and consenting to participate in the study, participants

137 completed demographic questions relating to their age, sex, schooling, locality (rural or urban),

138 income, and occupation. Following these, participants read a vignette (random allocation to one of

139 three vignettes with either a male or female protagonist) designed to emulate one of the three most

140 common types of mental illness: major depressive episode $(n=119)$, generalized anxiety disorder $(n=$

141 124), and psychosis $(n=130)$. Each vignette described an individual who was experiencing symptoms

142 of mental illness at a clinically significant level in which some form of intervention would be

143 recommended as per the criteria stipulated in the Diagnostic and Statistical Manual of Mental

144 Disorders 5 (DSM-V; American Psychiatric Association [APA], 2013). The depression and psychosis

145 vignettes were adapted from the depression and schizophrenia vignettes used by Jorm et al. (1997).

146 The names 'John' and 'Jane' were chosen for use in the vignettes due to the fact that they are

147 common Australian names with no cultural association to any minority groups. The age of the

148 protagonist was kept consistent at 30 years of age in order to avoid the potential confound of

149 developmental and psychosocial difficulties that often occur in childhood and adolescence as well as to

150 avoid age-specific neurological and physical conditions often present in older adults. Participants were

151 initially asked, in an open-ended question, to identify the disorder presented in the vignette. (i.e., "In

152 five words or less, what would you say, if anything, is wrong with the individual in the vignette?").

153 Additional forced choice questions, rated from 0 to 6 , were designed to ascertain: (a) participants'

154 perceptions of the seriousness of the symptoms described (i.e., "To what extent would you rate the

155 problems of the individual in the story as being serious?'); (b) the likelihood that treatment might be

156 required (i.e., "To what extent would some form of treatment or intervention be required for the 
157 individual in the story?"); and (c) the perceived level of control the individual in the vignette has over

158 the symptoms described (i.e., "To what extent are the problems of the individual in the story within his 159 or her control?").

160 The final questions related to participants' sex perceptions regarding mental illness (e.g., "Which 161 group of people would you consider to be most likely to experience problems similar to those of the 162 individual in the story?"). Participants were required to respond by choosing whether males, females, 163 or both were equally likely to experience problems.

164 The following overall guidelines were established for the purposes of providing consistency and accuracy in distinguishing between correct and incorrect responses to the above questions: (a) the use of the general category of mental illness (i.e., depression, anxiety, and psychosis), or a derivative of the word (e.g., depressive, depressed, anxious, or psychotic) was regarded as a correct response; (b) the use of the exact $D S M-V$ diagnostic criteria, or subtype there of (e.g., major depression, dysthymia, generalised anxiety disorder, or paranoid schizophrenia) was also regarded as a correct response; (c) references to symptoms of a mental illness rather than the illness itself were not regarded as correct responses; (d) the term "stressed" was not accepted as a correct identification of anxiety on the basis that it is frequently used as a colloquial term that can encompass a broad range of symptoms, some of

173 which are often not associated with anxiety. Similarly, the terms "paranoid" and "delusional" were not 174 accepted as correct identification of psychosis as they may also be used in colloquial contexts, and 175 refer to the symptoms of schizophrenia rather than the illness itself; (e) misspelt words or phrases were 176 accepted as correct providing it was discernible as to what mental illness was intended; and (f) accurate responses were maintained as correct regardless of additional information or diagnoses that were

178 provided beyond that of the correct diagnosis, as the participant demonstrated the ability to identify the 179 mental illness in question.

180 The study took approximately 15 minutes to complete. 


\section{Statistical Analysis}

All statistical analyses were conducted using SPSS Version 21. Chi-square was utilized to examine associations between nominal variables including identification of type of illness, participant and protagonist sex, and susceptibility of mental illness. Analysis of variance (ANOVA) was used to examine group differences in the outcome (interval level) variables including perceived seriousness, need for treatment, and personal control.

\section{Results}

\section{Identification of Mental Illness}

Hypothesis 1 related results that showed there was a strong association between correct identification and type of mental illness, $\chi^{2}(2, N=373)=52.11, p<.001, \phi=.37$, with $86 \%$ of participants correctly identifying depression, 57\% of participants correctly identifying anxiety, and $42 \%$ correctly identifying schizophrenia. Testing Hypothesis 2 showed that there was also a weak but statistically significant association between correct identification and sex, $\chi^{2}(1, N=373)=4.70, p=$ $.03, \phi=-.11$, with $52 \%$ of male and $64 \%$ of female participants correctly identifying the mental illness. Examining Hypothesis 3 showed that there was only a weak association between correct identification and protagonist sex, $\chi^{2}(1, N=373)=0.33, p=.056, \phi=.03$, with $62 \%$ of male and $59 \%$ of female protagonist mental illness correctly identified.

\section{The Need for Treatment}

$$
\text { Four three-way between groups ANOVAs, type of illness by sex by protagonist sex, were }
$$
conducted for perceived seriousness, need for treatment, and personal control, see Table 1. The means and standard deviations are reported in Table 2 along with any post hoc analysis of main effects.

$$
\text { The interaction effect between mental illness and participant sex was significant for need for }
$$
treatment, indicating that the effect that participant sex has on the perceived need for treatment for mental illness is dependent on the type of mental illness, see Figure 1. Analysis of simple effects was 
205 conducted using separate one-way between groups ANOVAs to determine the independent effects of 206 participant sex and type of mental illness. For depression there was no significant difference between 207 participant sex, $F(1,117)=0.21, p=.65$, partial $\eta^{2}<.01$. For anxiety there was a significant difference 208 between participant sex, $F(1,122)=11.80, p=.001$, partial $\eta^{2}=.09$, with females $(M=4.89, S D=$ 209 1.17) perceiving a higher need for treatment than males $(M=4.09, S D=1.14)$. For psychosis there was 210 a significant difference between participant sex, $F(1,128)=13.84, p<.001$, partial $\eta^{2}=.10$, with 211 females $(M=6.27, S D=0.79)$ perceiving a higher need for treatment than males $(M=5.64, S D=$ $2121.02)$.

213 


\section{Perceived Level of Control}

215 There was a significant interaction between participant and protagonist sex for personal control,

216 see Table 1, indicating that the effect that participant sex has on perceived level of control over mental

217 illness is dependent on the type of protagonist sex. Analysis of simple effects was conducted using

218 separate one-way between groups ANOVAs to determine the effects of participant and protagonist sex.

219 For males there was no significant difference between protagonist sex, $F(1,104)=3.05, p=.08$, partial

$220 \eta^{2}=.03$. For females there was no significant difference between the protagonist sex, $F(1,265)=0.74$,

$221 p=.39$, partial $\eta^{2}<.01$. For male protagonists there was no significant difference between participant

$222 \operatorname{sex}, F(1,180)=0.23, p=.64$, partial $\eta^{2}<.01$. For female protagonists there was a significant

223 difference between participant sex, $F(1,189)=10.77, p=.001$, partial $\eta^{2}=.05$, with male participants

224 rating a higher level of perceived control than females, see Figure 2.

225 Perceived Sex Susceptibility

226 Three chi-square tests were performed to test if there was a relationship between perceived sex

227 susceptibility and the type of mental illness, participant sex, and protagonist sex. There was a

228 significant association between perceived sex susceptibility and type of mental illness, $\chi^{2}(4, N=373)=$

$22922.48, p<.001, \phi=.25$. From the participants who received the depression vignette, $13.8 \%$ indicated

230 that males are more susceptible, $15 \%$ indicated that females are more susceptible, and $72 \%$ indicated

231 that males and females are equally susceptible. From the participants who received the anxiety

232 vignette, $13 \%$ indicated that males are more susceptible, $23 \%$ indicated that females are more

233 susceptible, and 63\% indicated that males and females are equally susceptible. From the participants

234 who received the psychosis vignette, $28 \%$ indicated that males are more susceptible, $6 \%$ indicated that

235 females are more susceptible, and 66\% indicated that males and females are equally susceptible.

236 There was a significant association between perceived sex susceptibility and participant sex, $\chi^{2}(2$,

$237 N=373)=11.00, p=.004, \phi=.17$. From the male participants, $29 \%$ indicated that males are more 
238 susceptible, $9 \%$ indicated that females are more susceptible, and $62 \%$ indicated that males and females

239 are equally susceptible. From the female participants, $15 \%$ indicated that males are more susceptible,

$24017 \%$ indicated that females are more susceptible, and $68 \%$ indicated that males and females are equally 241 susceptible.

\section{Post Hoc Analysis: Sex Susceptibility}

243 For methodological reasons we examined whether participants would regard the sex of the

244 protagonist as important to their susceptibility to mental illness. There was a significant association

245 between perceived sex susceptibility and protagonist sex, $\chi^{2}(2, N=373)=35.70, p<.001, \phi=.31$.

246 From the participants who received a male protagonist vignette, $29 \%$ indicated that males are more

247 susceptible, $6 \%$ indicated that females are more susceptible, and $65 \%$ indicated that males and females

248 are equally susceptible. From the participants who received a female protagonist vignette, $9 \%$ indicated

249 that males are more susceptible, $22 \%$ indicated that females are more susceptible, and $69 \%$ indicated

250 that males and females are equally susceptible.

\section{Discussion}

This study explored whether the mental health literacy of members of the general public was

253 influenced by (a) the type of mental illness, (b) the sex of the individual experiencing the symptoms of

254 mental illness, and (c) the sex of the individual identifying and appraising the mental illness.

255 Participants read a vignette describing either a male or female experiencing clinically significant

256 symptoms of depression, anxiety, or psychosis. Participants were then asked a number of questions in

257 order to assess various aspects of their mental health literacy. The results were consistent with the

258 hypothesis that some aspects of mental health literacy are influenced by the type of mental illness, sex

259 of the participant, and sex of the protagonist.

260 As hypothesized, the type of mental illness directly influenced participants' abilities to accurately

261 identify the presenting symptoms, with depression resulting as the most readily identifiable mental 
262 illness $(85.7 \%)$, followed by anxiety (56.5\%), and then psychosis $(41.5 \%)$. These findings suggest that

263 the general public is relatively good at identifying symptoms of depression, but find it significantly

264 more difficult to identify anxiety and psychosis. This is consistent with previous research that has

265 shown depression to be more readily identifiable by the general public than psychosis (e.g., Reavley \&

266 Jorm, 2011). A number of factors may contribute to the increased recognition of depression over

267 anxiety and psychosis. First, a greater prevalence of depression and anxiety in Australia compared to

268 psychosis may result in members of the general public having greater exposure and experience with

269 such mental illnesses. Second, given the exposure provided by organizations such as beyondblue, the

270 term depression is more readily used in the Australian vernacular and is associated with milder social

271 stigmas (Jorm et al., 2005b). Finally, compared to depression and anxiety, which refer to broad

272 categories of psychological symptoms, psychosis refers to a more specific set of psychological

273 symptoms outlined in the $D S M-V$, subsequently making it more difficult to accurately identify (APA,

274 2013; ABS, 2009).

275 Across the measures of level of seriousness, participants showed the greatest level of concern

276 towards individuals with psychosis, followed by depression, and anxiety. This is consistent with

277 evidence that has shown that psychosis and depression are associated with an increased level of

278 morbidity and mortality, when compared to the general population, and in particular, as relates to

279 serious cardiovascular events (Casey et al., 2004; Musselman, Evans \& Nemeroff, 1998; Wulsin,

280 Vaillant \& Wells, 1999). Similarly, psychosis and depression are associated with increased levels of

281 suicide attempts compared to the general population. In fact, suicide is the leading cause of premature

282 death among individuals with schizophrenia (Fenton, 2010). These findings suggest that the general

283 public have accurate perceptions of the seriousness of mental illnesses and support the finding by

284 Reavley and Jorm (2012) which identified a growing trend of improved mental health literacy of the

285 general public over the past decade. As hypothesized, a significant difference existed between each 
participant sex and their respective ability to accurately identify the presenting symptoms, with $64 \%$ of

287 females able to correctly identify the mental illness provided compared to $52 \%$ of males. Across the measures of level of seriousness, females displayed an overall tendency to perceive the symptoms of mental illness as more serious compared to males. These findings are congruent with previous studies suggesting that when compared with females, males display a poorer ability to correctly identify

291 mental illness as well as more definitive (if imprecise) attitudes towards the various aspects of mental 292 illness (Cotton et al., 2006; Kaneko \& Motohashi, 2007). For example, in Cotton et al.’s study, males

293 believed that the prevalence of mental illness was only $1 \%$ and that treatment by a medical professional was unlikely for psychosis. One possible explanation for these findings is that females may be inherently more psychologically minded, introspective, and emotionally aware, thus increasing the likelihood that they would (a) engage in conversations relating to emotional and psychological difficulties, (b) have contact or interactions with individuals who have a mental illness, and/or (c) participate in studies relating to mental health literacy (Petrides, Furnham \& Martin, 2004). Finally, as hypothesized, the sex of the protagonist presented in the vignette provided had an 301 degree of personal control, and sex susceptibility. Individuals who received a vignette with a male 302 protagonist displayed a tendency to report marginally higher levels of perceived seriousness compared 303 to individuals who read about a female protagonist. Furthermore, of the individuals provided with a 304 male protagonist vignette, $29 \%$ indicated that males were more likely to be susceptible to mental 305 illness compared to $6 \%$ of individuals who indicated that females were more likely. Conversely, when 306 presented with a female protagonist vignette the opposite trend was observed, with $22 \%$ indicating that 307 females were more likely to be susceptible to mental illness compared to $9 \%$ of individuals who 308 indicate that males were more likely. However, it is worth noting that the majority of participants considered both males and females as equally susceptible. Considering need for treatment, results 
310 indicated that participant, and not protagonist, sex was the principal factor. This was true for anxiety

311 and psychosis only, with females more likely than males to indicate that treatment was required for

312 these conditions. This finding is consistent with previous research (e.g., Holzinger et al., 2012) that

313 also indicates that females are more likely to endorse professional help for mental illness than males.

314 Further findings indicated that when provided with a female protagonist vignette, males displayed a

315 tendency to perceive a higher level of personal control over mental illness than females. However,

316 when provided with a male protagonist vignette no sex differences were observed. These results are

317 consistent with, and build upon, preliminary evidence obtained by Jorm et al. (1997) by suggesting that

318 protagonist sex may influence mental health literacy not only through self-reported beliefs, but also as

319 a result of innate perceptions regarding mental illness.

\section{Limitations}

321 Similar to other research conducted regarding mental health literacy, this research adopted the 322 use of a brief written vignette. The use of such a vignette presents two distinct complications. First, it is 323 uncertain whether a written description of symptoms of mental illness elicits the same attitudes and 324 perceptions as obtaining the same information from face-to-face observations and verbal 325 communication. It is likely that overt body language and non-verbal communication (i.e., facial 326 expressions, eye contact, tone of voice) would provide additional information from which to identify 327 and evaluate an individual's symptoms of mental illness.

328 Second, it is unknown whether the level of concern expressed towards a vignette of mental 329 illness is comparable or equivalent to that expressed towards a real person and whether there are any 330 differences in the subsequent therapeutic actions taken from such concern (i.e., help seeking behavior). 331 About $72 \%$ of the participants in the present study were females. ). Such a discrepancy may have 332 potentially created an overrepresentation of female beliefs and attitudes when performing comparisons 333 based on the entire sample. However, there were no statistically significant sex related interactions 
334 except for need for treatment. Due to a limited sample size and the scope of the initial aims in the

335 present study, we were not able to control for various demographics. However, the data set is available

336 (Gibbons, Thorsteinsson, \& Loi, 2015) and can be used in conjunction with similar information to

337 enhance power in future analyses.

338 The vignettes employed in this study depicted three different mental illnesses clearly

339 distinguishable from each other through the absence of overlapping symptoms or comorbid diagnoses

340 involving substance abuse, medical conditions, trauma, personality disorders, or intellectual

341 difficulties. Comorbidity among mental illness is extremely high and would inevitably have a large

342 impact on an individual's ability to accurately identify and evaluate mental illness. As such, the

343 findings from this study may not be extrapolated to apply to common situations whereby comorbidity

344 is present (Kessler et al., 2005). Similarly, the vignettes utilized in this study described the protagonists

345 as being 30 years of age in order to maintain consistency. Unique age-related difficulties in younger

346 (e.g., puberty) and older populations (e.g., cognitive decline) may potentially complicate the

347 identification of mental illness (Bartels, 2004; Pottick, Hansell, Gutterman \& Raskin-White, 1995).

348 Future research on mental health literacy may consider several issues: (a) considering whether

349 the trends displayed using vignettes are comparable to 'real life' symptoms, (b) the extent to which

350 expressed concerns towards mental illness equate to therapeutic action, (c) the influence of

351 comorbidity towards mental health literacy, (d) the influence of the age of the protagonist, (e) the effect

352 of utilizing a vignette describing sub-clinical everyday problems as a comparison, (f) exploration of the

353 possible reasons behind participants' mental health literacy, and (g) examining comparisons between

354 the mental health literacy of adolescents and adults. While studies comparing the mental health literacy

355 of different age groups within adolescent and adult populations (e.g., Farrer et al., 2008; Jorm, Morgan,

356 \& Wright, 2008), no research has compared adolescents and adults within the same study. 


\section{Conclusions}

358 The findings from this study suggest that the Australian general public is relatively proficient at 359 correctly identifying mental illness, in particular symptoms of depression. The general public also 360 displayed relatively accurate perceptions of the severity and seriousness of symptoms of depression, 361 anxiety, and psychosis. Males exhibited poorer mental health literacy skills than females, with males 362 being less likely to correctly identify the type of mental illness, displaying a tendency to rate symptoms 363 as being less serious, and perceiving greater personal control over mental illness. These findings help 364 to identify the area of public mental health literacy that may be improved in the Australian general 365 public, namely education programs targeted towards increasing awareness of mental illness in the male 366 population. Increased awareness of how gender may potentially influence people's ability to identify 367 mental illness and subsequently evaluate its severity may help to guide mental health professionals in 368 clinical decision making. In addition, this awareness may assist the general public make more accurate 369 'lay appraisals' of mental illness; however, further research is needed in order to determine whether the 370 public's attitudes and beliefs towards mental health literacy derived from vignette research is equivocal 371 to that derived from real life face-to-face consultations and how such beliefs and attitudes impact on 372 actual help-seeking behaviours. 
376 Alonso, J, Angermeyer, MC, Bernert, S, Bruffaerts, R, Brugha, TS, Bryson, H,...Vollebergh, WAM. 27 doi: 10.1111/j.1600-0047.2004.00327.x

American Psychiatric Association 2013. Diagnostic and statistical manual of mental disorders (5 $5^{\text {th }}$ ed.).

$$
\text { Washington, DC: Author. }
$$

Andrews, G. 1999. Efficacy, effectiveness, and efficiency in mental health service delivery. Australian and New Zealand Journal of Psychiatry, 33:316-322 doi: 10.1046/j.1440-1614.1999.00581.x.

Angermeyer, MC, Matschinger, H, Holzinger, A. 1998. Gender and attitudes towards people with schizophrenia. Results of a representative survey in the Federal Republic of Germany. International Journal of Social Psychiatry, 44:107-116.

Australian Bureau of Statistics 2008. National Survey of Mental Health and Wellbeing: Summary of results, 2007 (Cat No. 4326.0). Available at http://www.abs.gov.au/ausstats/abs@.nsf/Latestproducts/4326.0Main\%20Features32007?opend ocument\&tabname $=$ Summary $\&$ prodno $=4326.0 \&$ issue $=2007 \&$ num $=\& v i e w=$

Australian Bureau of Statistics 2009. Australian social trends in mental health: Summary of findings (Cat No. 4102.0). Available at http://www.abs.gov.au/AUSSTATS/abs@.nsf/Lookup/4102.0Main+Features30March\%202009

Bartels, SJ. 2004. Caring for the whole person: Integrated health care for older adults with severe mental illness and medical comorbidity. Journal of the Geriatrics Society, 52:249-257 doi: 10.1111/j.1532-5415.2004.52601.x. 
398 Burgess, PM, Pirkis, JE, Slade, TN, Johnston, AK, Meadows, GN, Gunn, JM. 2009. Service use for mental health use: Findings from the 2007 National Survey of Mental Health and Wellbeing. Australian and New Zealand Journal of Psychiatry, 43:615-623 doi:

\section{2} $10.1080 / 00048670902970858$.

Casey, DE, Haupt, DW, Newcomer, JW, Henderson, DC, Sernyak, MJ, Davidson, M,...Hennekens, CH. 2004. Antipsychotic-induced weight gain and metabolic abnormalities: Implications for increased mortality in patients with schizophrenia. Journal of Clinical Psychiatry, 65:4-18.

Cotton, SM, Wright, A, Harris, MG, Jorm, AF, McGorry, PD. 2006. Influence of mental health literacy in young Australians. Australian and New Zealand Journal of Psychiatry, 40:790-796 doi: 10.1111/j.1440-1614.2006.01885.x.

Dahlberg, KM, Waern, M, Runeson, B. 2008. Mental health literacy and attitudes in a Swedish community sample: Investigating the role of personal experience of mental health care. $B M C$ Public Health, 8:8-18 doi: 10.1186/1471-2458-8-8.

Farrer, L, Leach, L, Griffiths, KM, Christensen, H, Jorm, AF. 2008. Age differences in mental health literacy. BMC Public Health, 8:125-133 doi: 10.1186/1471-2458-8-125.

Fenton, WS. 2010. Depression, suicide, and suicide prevention in schizophrenia. Suicide and LifeThreatening Behavior, 30:34-49 doi: 10.1111/j.1943-278X.2000.tb01063.x.

Gibbons, R, Thorsteinsson, EB, Loi, NM. 2015. Sex differences in beliefs and attitudes towards mental illness: An examination of mental health literacy in a community sample [Data file]. Available at http://dx.doi.org/10.6084/m9.figshare.1392513.

418 Goldney, RD, Fisher, LJ, Wilson, DH. 2001. Mental health literacy: An impediment to the optimum 419 treatment of major depression in the community. Journal of Affective Disorders, 64:277-284 doi: 420 10.1016/S0165-0327(00)00227-5. 
421 Greenley, JR, Mechanic, D. 1976. Social selection in seeking help for psychological problems. Journal of Health \& Social Behavior, 17:249-262 doi: 10.2307/2136546.

423 Griffiths, KM, Christensen, H, Jorm, AF. 2009. Mental health literacy as a function of remoteness of residence: An Australian national study. BMC Public Health, 9:92-112 doi: 10.1186/1471-24589-92.

426

Hollingshead, AB. 2007. Social class and mental illness: A community study. American Journal of Public Health, 97:1756-1757 doi: 10.2105/AJPH.97.10.1756.

Holzinger, A, Floris, F, Schomerus, G, Carta, MG, Angermeyer, MC. 2012. Gender differences in public beliefs and attitudes about mental disorder in western countries: A systematic review of population studies. Epidemiology and Psychiatric Sciences, 21:73-85 doi: $10.1017 / \mathrm{S} 2045796011000552$.

Jorm, AF, Barney, LJ, Christensen, H, Highet, NJ, Kelly, CM, Kitchener, BA. 2006. Research on mental health literacy: What we know and what we still need to know. Australian and New Zealand Journal of Psychiatry, 40:3-5 doi: 10.1111/j.1440-1614.2006.01734.x.

Jorm, AF, Christensen, H, Griffiths, KM. 2005a. Belief in the harmfulness of antidepressants: Results from a national survey of the Australian public. Journal of Affective Disorders, 88:47-53 doi: 10.1016/j.jad.2005.06.002.

Jorm, AF, Christensen, H, Griffiths, KM. 2005b. The impact of beyondblue: the national depression initiative on the Australian public's recognition of depression and beliefs about treatments. Australian and New Zealand Journal of Psychiatry, 39:248-254 doi: 10.1111/j.14401614.2005.01561.x.

Jorm, AF, Christensen, H, Griffiths, KM. 2006. The public's ability to recognize mental disorders and their beliefs about treatment: Changes in Australia over 8 years. Australian \& New Zealand Journal of Psychiatry, 40:36-41 doi: 10.1111/j.1440-1614.2006.01738.x. 
445 Jorm, AF, Christensen, H, Medway, J, Korten, AE, Jacomb, PA, Rodgers, B. 2000. Public beliefs about 446 the helpfulness of interventions for depression: Effects on actions taken when experiencing anxiety and depression symptoms. Australian and New Zealand Journal of Psychiatry, 34:619626 doi: 10.1046/j.1440-1614.2000.00761.x.

$450 \quad$ Australian Psychologist, 42:81-89 doi: 10.1080/00050060701280565.

451 Jorm, AF, Korten, AE, Jacomb, PA, Christensen, H, Rogers, B, Pollitt, P. 1997. Public beliefs about 452 causes and risk factors for depression and schizophrenia. Social Psychiatry and Psychiatric Epidemiology, 32:143-148 doi: 10.1007/bf00794613.

454 Jorm, AF, Morgan, AJ, Wright, A. 2008. First aid strategies that are helpful to young people 455 developing a mental disorder: Beliefs of health professionals compared to young people and 456 parents. BMC Psychiatry, 8:42 doi: 10.1186/1471-244X-8-42.

\section{9} 460

Kaneko, Y, Motohashi, Y. 2007. Male gender and low education with poor mental health literacy: A population-based study. Journal of Epidemiology, 17:114-119 doi: org/10.2188/jea.17.114.

Kessler, RC, Berglund, P, Zhao, S, Demler, O, Jin, R, Merikangas, KR, Walters, EE. 2005. Lifetime prevalence and age-of-onset distributions of $D S M-I V$ disorders in the national comorbidity survey replication. Archives of General Psychiatry, 62:593-602 doi:10.1001/archpsyc.62.6.593.

Kessler, RC, McGonagle, KA, Zhao, S, Nelson, CB, Hughes, M, Eshleman, S, Wittchen, H-U, Kendler, KS. 1994. Lifetime and 12-month prevalence of DSM-III-R psychiatric disorders in the United States: Results from the national comorbidity survey. Archives of General Psychiatry, 51:8-19 doi:10.1001/archpsyc.1994.03950010008002.

Link, BG, Phelan, JC, Bresnahan, M, Stueve, A, Pescosolido, BA. 1999. Public conceptions of mental illness: Labels, causes, dangerousness, and social distance. American Journal of Public Health, 89:1328-1333 doi: 10.2105/AJPH.89.9.1328. 
469 Musselman, DL, Evans, DL, Nemeroff, CB. 1998. The relationship of depression to cardiovascular disease: Epidemiology, biology, and treatment. Archives of General Psychiatry, 55:580-592 doi:10.1001/archpsyc.55.7.580.

Pescosolido, BA, Gardner, CB, Lubell, KM. 1998. How people get into mental health services: Stories of choice, coercion and 'muddling through' from 'first-timers'. Social Science \& Medicine, 46:275-286 doi: 10.1016/S0277-9536(97)00160-3.

Petrides, KV, Furnham, A, Martin, GN. 2004. Estimates of emotional and psychometric intelligence:

$$
\text { Evidence for gender-based stereotypes. Journal of Social Psychology, 144:149-162 doi: }
$$

$$
\text { 10.3200/SOCP.144.2.149-162. }
$$

Pottick, K, Hansell, S, Gutterman, E, Raskin-White, HR. 1995. Factors associated with inpatient and outpatient treatment for children and adolescents with serious mental illness. Journal of the American Academy of Child and Adolescent Psychiatry, 34:425-433 doi: 10.1097/00004583199504000-00009.

Reavley, NJ, Jorm, AF. 2011. Recognition of mental disorders and beliefs about treatment and outcome: Findings from an Australian national survey of mental health literacy and stigma. Australian and New Zealand Journal of Psychiatry, 45:947-956 doi: $10.3109 / 00048674.2011 .621060$.

Reavley, NJ, Jorm, AF. (2012). Public recognition of mental disorders and beliefs about treatment: Changes in Australia over 16 years. British Journal of Psychiatry, 200:419-425 doi: 10.1192/bjp.bp.111.104208.

Sane Australia. 2014. Facts and figures about mental illness [Fact sheet]. Available at http://www.sane.org/images/stories/information/factsheets/fs 13 facts\&figures.pdf

Wulsin, LR, Vaillant, GE, Wells, VE. 1999. A systematic review of the mortality of depression. Psychosomatic Medicine, 61:6-17. 
493

494

PeerJ reviewing PDF | (2015:04:4611:2:0:NEW 13 May 2015) 
Table $\mathbf{1}$ (on next page)

Between Groups ANOVAs for the Effects of Illness, Gender, and Protagonist Gender on Perceived Seriousness, Need for Treatment, and Personal Control 


\section{Table 1}

3 Between Groups ANOVAs for the Effects of Illness, Sex, and Protagonist Sex on Perceived Seriousness,

4 Need for Treatment, and Personal Control

\begin{tabular}{lcccccc}
\hline & \multicolumn{2}{c}{ Perceived Seriousness } & \multicolumn{2}{c}{ Need for Treatment } & \multicolumn{2}{c}{ Personal Control } \\
\cline { 2 - 7 } Measures & $F$ & Partial $\eta^{2}$ & $F$ & Partial $\eta^{2}$ & $F$ & Partial $\eta^{2}$ \\
\hline Illness type (I) & $69.74^{* * *}$ & .28 & $49.81^{* * *}$ & .22 & $20.50^{* * *}$ & .10 \\
Sex (S) & $6.19^{*}$ & .02 & $18.29^{* * *}$ & .05 & $7.01^{* *}$ & .02 \\
Protagonist sex (PS) & $4.73^{*}$ & .01 & 1.04 & $<.01$ & 0.79 & $<.01$ \\
I $\times$ S & 2.01 & .01 & $3.11^{*}$ & .02 & 0.36 & $<.01$ \\
I $\times$ PS & 0.02 & $<.01$ & 0.16 & $<.01$ & 0.30 & $<.01$ \\
S $\times$ PS & 2.22 & .01 & 0.006 & $<.01$ & $4.70^{*}$ & .01 \\
I $\times$ S $\times$ PS & 0.76 & $<.01$ & 0.44 & $<.01$ & 1.42 & .01 \\
\hline
\end{tabular}

$5 \quad$ Note. ${ }^{*} p<.05, * * p<.01, * * * p<.001$

6 
Table 2 (on next page)

Means and Standard Deviations for Condition, Gender of participants and protagonist by the Perceived Seriousness, Need for Treatment, and Personal Control 


\section{Table 2}

3 Means and Standard Deviations for Condition, Sex of Participants and Protagonist by Perceived

4 Seriousness, Need for Treatment, and Personal Control

\begin{tabular}{llll}
\hline Measure & $\begin{array}{l}\text { Perceived } \\
\text { Seriousness }\end{array}$ & $\begin{array}{l}\text { Need for } \\
\text { Treatment }\end{array}$ & $\begin{array}{l}\text { Personal } \\
\text { Control }\end{array}$ \\
\hline Illness & & & \\
Depression & $5.57(1.04)_{\mathrm{a}}$ & $5.13(1.10)_{\mathrm{a}}$ & $3.81(1.37)_{\mathrm{a}}$ \\
Anxiety & $4.87(1.18)_{\mathrm{b}}$ & $4.67(1.21)_{\mathrm{b}}$ & $4.04(1.48)_{\mathrm{a}}$ \\
$\quad \begin{array}{l}\text { Psychosis } \\
\text { Participant }\end{array}$ & $6.46(0.75)_{\mathrm{c}}$ & $6.09(0.90)_{\mathrm{c}}$ & $2.86(1.56)_{\mathrm{b}}$ \\
Male & $5.46(1.30)_{\mathrm{a}}$ & $4.94(1.26)_{\mathrm{a}}$ & $3.87(1.49)_{\mathrm{a}}$ \\
$\quad \begin{array}{l}\text { Female } \\
\text { Protagonist }\end{array}$ & $5.72(1.14)_{\mathrm{b}}$ & $5.46(1.19)_{\mathrm{b}}$ & $3.43(1.57)_{\mathrm{b}}$ \\
Male & & & \\
Female & $5.74(1.20)_{\mathrm{a}}$ & $5.36(1.21)_{\mathrm{a}}$ & $3.56(1.64)_{\mathrm{a}}$ \\
& $5.57(1.19)_{\mathrm{b}}$ & $5.26(1.25)_{\mathrm{a}}$ & $3.55(1.48)_{\mathrm{a}}$
\end{tabular}

5 Note. Values within variables in columns that share a subscript are not different by alpha criterion of .05 (Sidak adjusted). 
Figure 1 (on next page)

Image of need for treatment expressed by male and female participants towards the three types of mental illness.

Need for treatment expressed by male and female participants towards the three types of mental illness. 


\section{PeerJ Reviewing Manuscript}

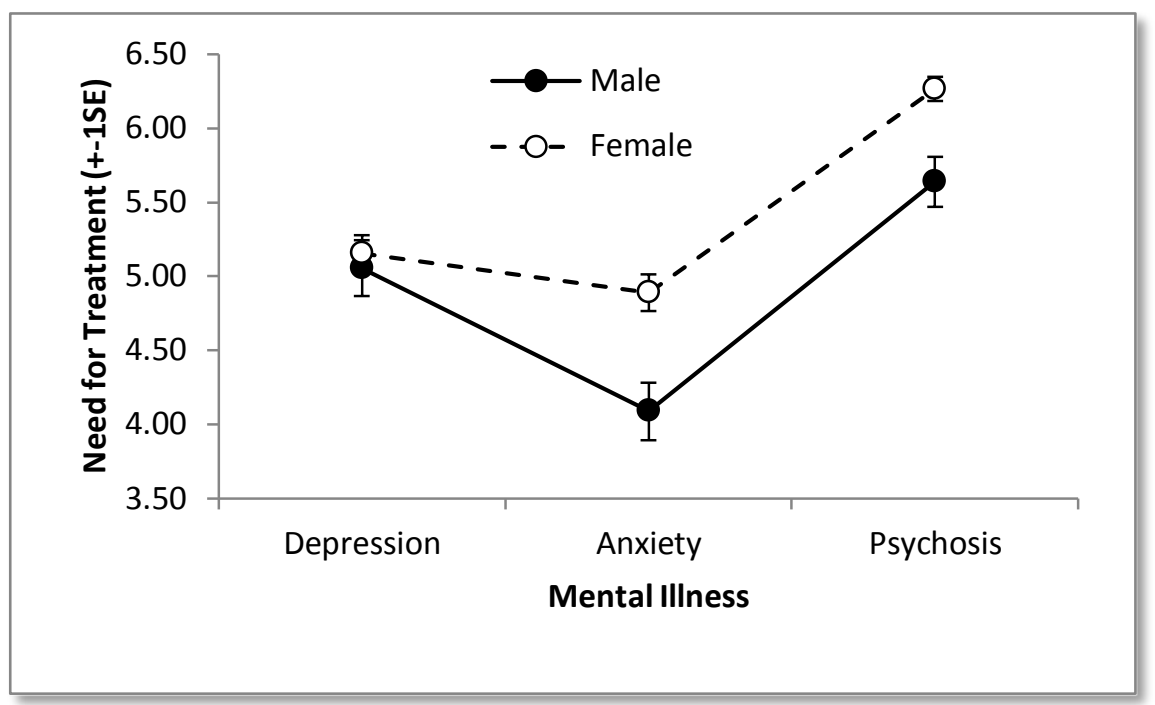


Figure 2 (on next page)

Image of perceived level of personal control over mental illness for each protagonist gender as rated by each participant gender.

Perceived level of personal control over mental illness for each protagonist gender as rated by each participant gender. 


\section{PeerJ Reviewing Manuscript}

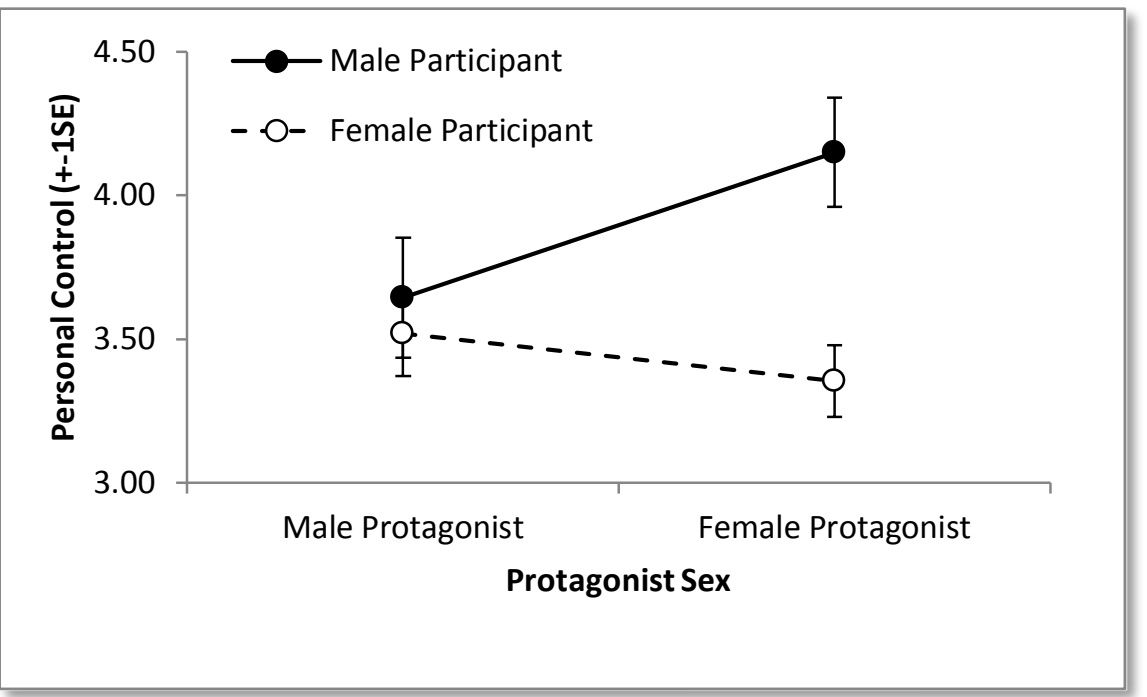

